\title{
The etiology of viral lower respiratory tract infections at a tertiary hospital in Jordan over five years
}

\author{
Isam Bsisu ${ }^{1}$, Zaina Obeidat ${ }^{1}$, Nidaa Ababneh ${ }^{2}$, \\ Mai Altous ${ }^{3}$, Mohammed Obeidat ${ }^{1}$, Mousa Amer ${ }^{1}$, \\ Mona Freihat ${ }^{4}$, Hanan Khalil ${ }^{5}$, Rasha Bsisu ${ }^{6}$, \\ Maisa Mansour ${ }^{7}$, Randa Farah ${ }^{8}$, Azmi Mahafzah ${ }^{9}$, \\ Nathir Obeidat ${ }^{7}$
}

\section{Abstract}

Background: The third leading cause of death worldwide is lower respiratory tract infection (LRTI), which is considered the most common condition treated in primary care. The objective of our study is to determine the etiological agents that cause viral LRTI in Jordan, aiming to help physicians to choose the appropriate treatment strategy.

Materials and Methods: A retrospective study was conducted on patients who were admitted with the diagnosis of LRTI between January 2011 and January 2016. We used Fast-track Diagnostics (FTD)® Respiratory 21 Kit (Fast-track Diagnostics, Luxembourg) real-time PCR to determine the viral etiology of LRTI, and we investigated pandemic H1N1 2009 swine flu (H1N1pdm009) virus using rapid test PCR (RTPCR; Cepheid GeneXpert@, California, USA).

Results: This study involved 495 patients with a mean age of 57.79 \pm 18.43 years. The causative agents were identified in 157 patients out of 495 patients (31.7\%). FTD real-time PCR was done for 170 patients, and the test was positive for seasonal Influenza A virus in $7.1 \%$ of patients, influenza B in $4.1 \%$, RSV in $4.7 \%$, metapneumovirus in $4.1 \%$, adenovirus in $4.1 \%$, coronavirus $229 \mathrm{E} / \mathrm{NL} 63$ in $4.1 \%$, parainfluenza virus in $7.6 \%$, and rhinovirus in $3.5 \%$. RT- PCR was done for 495 patients, and the percent of cases who were positive for $\mathrm{H} 1 \mathrm{~N} 1 \mathrm{pdm} 009$ virus was $4.2 \%$. The rate of ICU admission was $16.8 \%$, and the mortality rate of LRTI was as low as 3.6\%.
1 School of Medicine, University of Jordan, Amman, Jordan.

2 Cell Therapy Center, University of Jordan, Amman, Jordan.

3 Interventional Pulmonary and Critical Care Unit, King Hussein Cancer Foundation and Center, Amman, Jordan.

4 Department of Special Surgery, Jordan University Hospital, Amman, Jordan.

5 Internal Medicine Department, King Hussein Cancer Foundation and Center Amman, Jordan.

6 Department of Clinical Pharmacy, School of Pharmacy, University of Jordan, Amman, Jordan.

7 Pulmonary Medicine and Critical Care Unit, Internal Medicine Department, Jordan University Hospital, Amman, Jordan.

8 Internal Medicine Department, School of Medicine, University of Jordan, Amman, Jordan.

9 Department of Pathology, Microbiology and Forensic Medicine, School of Medicine, University of Jordan, Amman, Jordan

Contact information:

Isam Bsisu.

Address: School of Medicine, the University of Jordan. PO Box 13046, Amman, 11942, Jordan.

Tel: +962 65355000

Fax: +962 65355000

झ isam_bsisu@hotmail.com 
Conclusions: Viral LRTI is more common in winter season in Jordan, especially in January. Remarkably, Influenza A and Parainfluenza viruses were the main viral causative agents for LRTI in our study. This study suggests that the detection of viral infections in patients with LRTI can reduce the use of antibiotics and will slow development of antimicrobial resistance.

\section{Keywords}

Viral respiratory tract infection; LRTI; Pneumonia; Acute Bronchitis.

\section{Introduction}

Acute lower respiratory tract infection (LRTI) is the most common condition treated in primary care [1], and it was considered the third leading cause of death worldwide in 2017 [2]. According to recent studies, about 1.9 million adults above the age of 15 die from LRTIs each year [3], with the highest risk of mortality among elderly [4-6]. One of the major subtypes of LRTI is pneumonia, which is diagnosed by the presence of new respiratory symptoms including cough, fever, chills, rigors, chest pain, pleurisy, dyspnea and sputum production, and mental status changes, and physical exam findings such as respiratory rate $\geq 24$ breaths/minute, tachycardia, audible rales or bronchial sounds, leukocytosis with a left shift or leukopenia, in addition to new infiltrate on the chest $x$-ray $[7,8]$. Whereas the diagnosis of acute bronchitis is considered when there is no definite chest $x$-ray infiltrate. The annual incidence of pneumonia was 24.8 cases per 10,000 adults in the USA [9]. The incidence of LRTI differs according to the season, occurring more in winter and autumn [10], with $20-40 \%$ of adults being admitted to hospital as a consequence of having pneumonia [11].

Nowadays, viral causes of LRTI are being much more recognized. When comparing between conventional viral diagnostic methods (culture, antigen detection, and serological assays) and polymera- se chain reaction (PCR)-based assays, PCR-based methods are 2-5 times more sensitive in the detection of respiratory viruses [12]. The use of PCR has also increased the detection rate of viruses that are difficult to identify with conventional methods, including human rhinovirus (HRV), human coronavirus (hCoV), human metapneumovirus (hMPV), and human bocavirus $[13,14]$. Development of several multiplex PCR assays has enabled the simultaneous detection of multiple viruses in the same tube. [15]. Recently, the utilization of PCR techniques is becoming the standard method of choice for the identification of respiratory viruses [16-18].

The purpose of this study is to provide epidemiological data regarding the viral etiology of LRTI at our region considering their seasonal variation. By this, we will have more understanding of the causative agents of LRTI.

\section{Materials and Methods}

\section{Data collection and study design}

We retrospectively reviewed patients who were admitted to Jordan University Hospital (JUH) for signs and symptoms of LRTI between January 2011 and January 2016. We reviewed their medical records, laboratory results and radiological images. 
Additionally, we reviewed the patients' symptoms and signs elicited during the admission period. We documented the patients' date of admission. We took into consideration their gender, smoking habit (smoker/ non-smoker/ ex-smoker) and co-morbidities, such as diabetes mellitus (DM), pulmonary, cardiac, renal, and other co-morbidities. We also documented the site of admission, whether ICU or floor, also the patient's status on admission, including their level of consciousness, their blood pressure, their heart rate and respiratory rate. The patient's blood urea levels and creatinine levels were measured, as well as their electrolytes and their complete blood count (CBC). We referred to the patients' X-rays, to see if there were radiologic changes. We checked the results of the bacterial cultures and PCR results from blood samples, bronchoalveolar lavage fluid (BAL), sputum specimens, and nasopharyngeal swabs.

\section{Inclusion and exclusion criteria}

Patients above the age of 16 years admitted for LRTI under the care of pulmonary medicine and critical care primary team were included in this study. Acute bronchitis was defined as having fever $\left(>38^{\circ} \mathrm{C}\right)$, cough, increased sputum production, rhonchi, and wheezing, with no radiographic evidence of pneumonia. Pneumonia was defined when the previously mentioned symptoms of LRTI were accompanied by new or progressive lung infiltrate (i.e., increased density on chest X-ray due to the presence of pus, protein, or air within the parenchyma of the lung), consolidation, pleural effusion, or cavitation on chest X-ray [19]. We excluded patients diagnosed with hospital-acquired, ventilator-associated, and healthcare-associated pneumonia [20].

\section{Severity and complications of LRTI}

Severity of pneumonia was classified according to CURB65 mortality predictor for community acquired pneumonia, giving 1 point for each of the following characteristics: confusion, blood urea nitrogen $>7$ $\mathrm{mmol} / \mathrm{L}$, respiratory rate $>=30$ breaths/min, systolic blood pressure $<=90$, diastolic blood pressure $=<60$ $\mathrm{mmHg}$, and age 65 years or older. We followed up the patients until improvement and hospital discharge or death. Additionally, whether they have developed complications, including intubation for acute respiratory distress syndrome (ARDS), respiratory failure, and other complications like pleural effusion, septic shock, while sepsis was defined as life-threatening organ dysfunction caused by a dysregulated host response to infection [21], associated disseminated intravascular coagulation (DIC), myocardial infarction (MI), or renal complications.

The definition of clinical improvement was based on the clinical stability criteria drafted by Infectious Diseases Society of America and the American Thoracic Society (IDSA/ATS) as the following: patient's temperature $\leq 37^{\circ} \mathrm{C}$ (orally), heart rate $\leq 100$ beats/ min, respiratory rate $\leq 24$ breaths/min, systolic BP $\geq$ $90 \mathrm{mmHg}$, arterial oxygen saturation $\geq 90 \%$ or PO2 $\geq 60 \mathrm{mmHg}$ on room air, ability to maintain oral intake, and normal or baseline mental status [22].

\section{Laboratory diagnosis of LRTI viral etiology} We used Fast-track Diagnostics (FTD)® Respiratory 21 Kit (Fast-track Diagnostics, Junglinster, Luxembourg) real-time PCR which included the following pathogens: influenza $A$, influenza $B$, coronavirus NL63, 229E, OC43 and HKU1, parainfluenza 1,2,3 and 4 , human metapneumovirus $A$ and $B$, rhinovirus, respiratory syncytial viruses $A$ and $B$, adenovirus, enterovirus, parechoovirus, bacovirus, mycloplasma pneumonia[23]. In addition, we investigated pandemic H1N1 2009 swine flu virus (H1N1pdm009) rapid test PCR (RT-PCR; Cepheid GeneXpert $\AA$, Sunnyvale, California, USA), which is the method of choice for its clinical diagnosis [24].

\section{Statistical analysis}

For statistical analysis, we used SPSS (SPSS Inc., version 22.0, Chicago, Illinois, USA) software for analyzing the collected data. The data was analyzed using Pearson Chi-squared test ( $X^{2}$ test), as well as 
T-test. The analysis compared between viral pneumonia and acute bronchitis in their etiology, outcomes, and mortality rates, taking into considerations all other variables. The statistical significance for the results in all these two tailed statistical tests was considered as P-value $<0.05$.

\section{Results}

\section{Patients" characteristics}

This study involved 495 patients with a median age of 62 years, and a mean of $57.8 \pm 18.4$ years. A total of $274(55.4 \%)$ patients were males, and 221 $(44.6 \%)$ were females. Out of the 495 patients, 115 were smokers (23.2\%), 242 were non-smokers (48.9\%), 60 were ex-smokers (12.1\%), and 78 patients did not specify their smoking habit (15.8\%). Among the studied population, males showed higher prevalence of smoking (35\%), compared with only (8\%) for female patients. Approximately, 411 $(83 \%)$ of the patients have comorbidities (Table 1). Regarding the clinical diagnosis of these patients, 290 patients (58.6\%) were diagnosed to have pneumonia, and 205 (41.4\%) were diagnosed to have acute bronchitis. The presenting symptoms of LRTI varied between patients, but cough was reported by $91 \%$ of patients, making it the most common presenting symptom, followed by shortness of breath (SOB) which was reported in $79.6 \%$ of the cases, and sputum production came third with a percent of $67.8 \%$ (Figure 1). Among the 495 patients, 49 patients (9.9\%) developed complications during their hospitalization period (Table 2).

A total of $83(16.8 \%)$ patients were admitted to the intensive care unit (ICU) based on their CURB65 score (mean was $2.1 \pm 1.0$ ), and/or other factors (e.g. bilateral chest $\mathrm{X}$-ray infiltrates, multiple co-morbidities). Overall, 18 patients (3.6\%) have died during their hospitalization period.
Table 1. Patients demographics.

\begin{tabular}{|c|c|c|}
\hline Patient Characteristic & No. of Patients & $\%$ \\
\hline \multicolumn{3}{|l|}{ Age (years) } \\
\hline Mean Age + SD (yr) & \multicolumn{2}{|c|}{$57.79 \pm 18.43$ range [16-92] } \\
\hline Median Age & \multicolumn{2}{|l|}{62 years } \\
\hline \multicolumn{3}{|l|}{ Gender } \\
\hline Male & 274 & 55.4 \\
\hline Female & 221 & 44.6 \\
\hline \multicolumn{3}{|l|}{ Smoking } \\
\hline Current Smoker & 115 & 23.2 \\
\hline Ex-Smoker & 60 & 12.1 \\
\hline Non-Smoker & 242 & 48.9 \\
\hline Unknown & 78 & 15.8 \\
\hline Co-morbidities & 411 & 83.0 \\
\hline Cardiovascular Diseases & 272 & 55.0 \\
\hline Pulmonary diseases & 216 & 43.6 \\
\hline Diabetes Mellitus & 191 & 38.6 \\
\hline Renal Diseases & 57 & 11.5 \\
\hline Other co morbidities & 142 & 28.7 \\
\hline \multicolumn{3}{|c|}{ Number of Co-morbidities per patient } \\
\hline No co-morbidities & 85 & 17.2 \\
\hline One co-morbidity & 130 & 26.3 \\
\hline Two co-morbidities & 134 & 27.1 \\
\hline Three co-morbidities & 109 & 22 \\
\hline Four co-morbidities & 31 & 6.3 \\
\hline Five co-morbidities & 6 & 1.2 \\
\hline
\end{tabular}

Figure 1: Patients presenting symptoms.

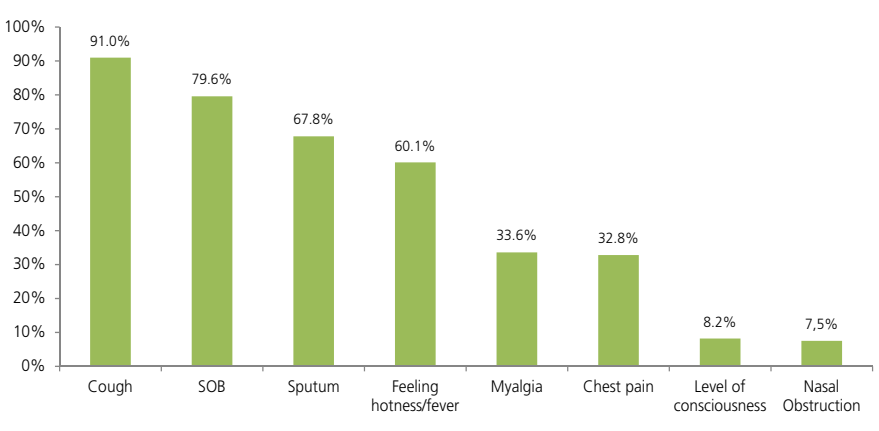

Patients presenting symptoms: the most frequent presenting symptoms for patients with viral LRTI, with each patient presenting with one or more of the mentioned symptoms. All of the patients were evaluated using $X$-ray. 
Table 2. Patients diagnosis, site of admission, CURB65 score, and complications.

\begin{tabular}{|l|c|c|}
\hline \multicolumn{1}{|c|}{ Clinical Characteristics } & No. of Patients & $\%$ \\
\hline Pneumonia & 290 & 58.6 \\
\hline Bronchitis & 205 & 41.4 \\
\hline Admission & & \\
\hline ICU & 83 & 16.8 \\
\hline Ward (in-patient) & 412 & 83.2 \\
\hline Mean CURB-65 score & $1.3 \pm 0.9$ \\
\hline Mean CURB-65 score for ICU & $2.1 \pm 1.0$ \\
\hline Complication & 49 & 9.9 \\
\hline Intubation & 10 & 2.0 \\
\hline Pleural Effusion & 26 & 5.3 \\
\hline septic shock & 6 & 1.2 \\
\hline Renal complications & 5 & 1.0 \\
\hline DIC & 2 & 0.4 \\
\hline MI & 4 & 0.8 \\
\hline Death & 18 & 3.6 \\
\hline
\end{tabular}

Table 3. Causative agents of viral LRTI.

\begin{tabular}{|c|c|c|}
\hline Clinical Characteristics & No. of Patients & $\%$ \\
\hline Pathogen & 157 & 31.7 \\
\hline Viral & 69 & 13.9 \\
\hline \multicolumn{3}{|l|}{ RT-PCR ( $n=495)$} \\
\hline Pandemic H1N1 Swine & 22 & 4.2 \\
\hline \multicolumn{3}{|l|}{ FTD $(n=170)$} \\
\hline Influenza A Seasonal & 12 & 7.1 \\
\hline Influenza B & 7 & 4.1 \\
\hline RSV & 8 & 4.7 \\
\hline metapneumovirus & 7 & 4.1 \\
\hline Adenovirus & 7 & 4.1 \\
\hline Coronavirus 229E/ NL63 & 7 & 4.1 \\
\hline Para Influenza & 13 & 7.6 \\
\hline Rhinovirus & 6 & 3.5 \\
\hline Bacteria & 105 & 21.2 \\
\hline
\end{tabular}

\section{The viral etiology results}

The causative agents were identified in 157 patients (31.7\%) (Table 3). We classified the patients according to the date of their admission, in order to investigate seasonal variation (Table $\mathbf{4}$ \& Figure 2 ). The rapid test for H1N1pdm009 virus was done for all 495 patients and was positive in 22 patients (4.2\%). FTD real-time PCR was done for 170, and the percentage of identified viruses were as the following: parainfluenza virus was $7.6 \%(n=13)$, seasonal Influenza A virus was $7.1 \%(n=12)$, influenza $B$ was $4.1 \%(n=7)$, RSV was $4.7 \%(n=8)$, metapneumovirus was $4.1 \%(n=7)$, adenovirus was $4.1 \%(n=7)$, coronavirus 229E/NL63 was $4.1 \%(n=7)$, rhinovirus was $3.5 \%(n=6)$ (Figure 3).

\section{Comparison between pneumonia and acute bronchitis}

As mentioned earlier, 290 patients (58.6\%) were diagnosed to have pneumonia, and 205 (41.4\%) were diagnosed to have acute bronchitis. The median age of pneumonia patients was 63 years, and a mean of $58.7 \pm 18.3$ years, with (159) $54.8 \%$ being males, and (131) $45.2 \%$ being females. In comparison, the median age was 59 years, and the mean was $56.6 \pm 18.5$ years for patients with acute bronchitis, with (115) 56.1\% being males, and (90) $43.9 \%$ being females. We have discussed the percentage of each causative agent for pneumonia and acute bronchitis individually in (Table 5).

Upon analyzing the table, none of the viral causative agents showed significant difference in the number of identified cases between acute bronchitis and pneumonia patients, and there was no significant seasonal variation between the two groups.

\section{ICU cases analysis}

From the 495 patients, 83 patients were admitted to the ICU, of which $57(68.7 \%)$ patients were pneumonia cases, while the other 26 (31.3\%) were cases of acute bronchitis. The patients median age 
Table 4. Monthly distribution of each of the viral causative agents of LRTI over five years.

\begin{tabular}{|c|c|c|c|c|c|c|c|c|c|c|c|c|c|}
\hline \multirow{2}{*}{ Characteristic } & \multicolumn{12}{|c|}{ Month } & \multirow{2}{*}{ Month } \\
\hline & Jan & Feb & Mar & Apr & May & Jun & Jul & Aug & Sep & Oct & Nov & Dec & \\
\hline H1N1pdm009 & 10 & 2 & 2 & 3 & 0 & 1 & 0 & 1 & 0 & 0 & 2 & 1 & 22 \\
\hline Influenza a & 5 & 3 & 1 & 0 & 0 & 0 & 0 & 0 & 0 & 1 & 0 & 2 & 12 \\
\hline Influenza B & 2 & 2 & 0 & 0 & 0 & 0 & 0 & 0 & 0 & 1 & 1 & 1 & 7 \\
\hline RSV & 3 & 3 & 1 & 0 & 0 & 0 & 0 & 0 & 0 & 0 & 1 & 0 & 8 \\
\hline Metapneumovirus & 1 & 2 & 1 & 0 & 0 & 0 & 0 & 0 & 1 & 1 & 1 & 0 & 7 \\
\hline Adenovirus & 0 & 1 & 1 & 0 & 1 & 1 & 0 & 0 & 1 & 1 & 1 & 0 & 7 \\
\hline Coronavirus 229E/ NL63 & 0 & 1 & 1 & 0 & 1 & 1 & 0 & 0 & 1 & 1 & 1 & 0 & 7 \\
\hline Parainfluenza virus & 2 & 2 & 3 & 1 & 1 & 1 & 0 & 0 & 0 & 2 & 1 & 0 & 13 \\
\hline Rhinovirus & 2 & 2 & 0 & 0 & 0 & 0 & 0 & 0 & 1 & 0 & 0 & 1 & 6 \\
\hline Sum & 25 & 18 & 10 & 4 & 3 & 4 & 0 & 1 & 4 & 7 & 8 & 5 & 89 \\
\hline
\end{tabular}

This table shows the distribution of cases per month for each of the studied viruses from January 2011 to January 2016.

Figure 2: Monthly distribution of viral and bacterial LRTI.

_Cases with viral infection _Cases with bacterial infection

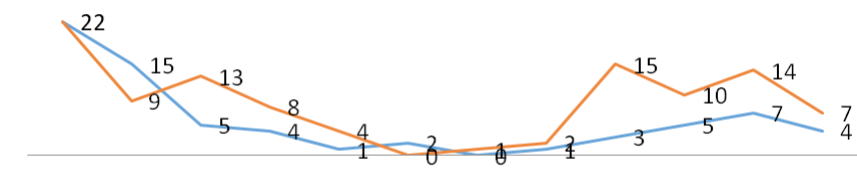

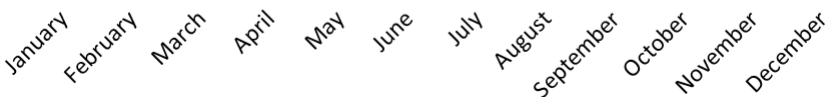

Monthly distribution of viral and bacterial LRTI: The figure shows the count of cases per month over the period of 5 years, showing the increase in viral LRTI in autumn and that it peaks in winter.

Figure 3: Incidence of each viral causative agent of LRTI.

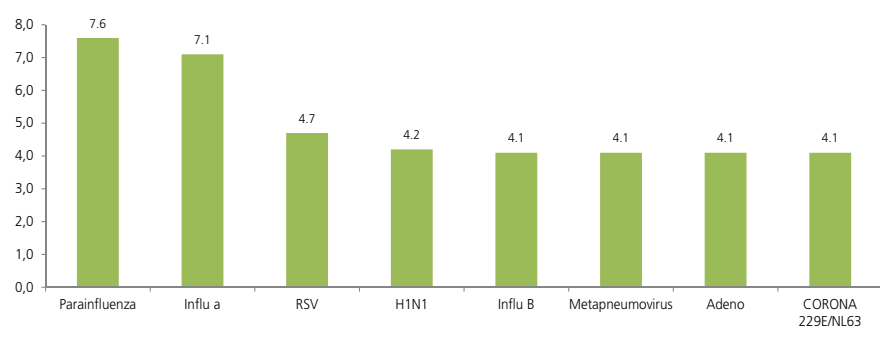

Incidence rates of each viral causative agent of LRTI.
Table 5. Monthly distribution of each of the viral causative agents of LRTI over five years.

\begin{tabular}{|c|c|c|c|c|c|}
\hline \multirow{2}{*}{$\begin{array}{c}\text { Causative } \\
\text { Agent }\end{array}$} & \multicolumn{2}{|c|}{$\begin{array}{l}\text { Pneumonia } \\
(n=290)\end{array}$} & \multicolumn{2}{|c|}{$\begin{array}{l}\text { Acute Bronchitis } \\
\quad(n=205)\end{array}$} & \multirow[t]{2}{*}{ P-value } \\
\hline & Positive & $\%$ & Positive & $\%$ & \\
\hline H1N1pdm009 & 10 & 3.4 & 12 & 5.9 & 0.201 \\
\hline $\begin{array}{l}\text { Influenza A } \\
\text { Seasonal }\end{array}$ & 8 & 2.8 & 4 & 2.0 & 0.768 \\
\hline Influenza B & 5 & 1.7 & 2 & 1.0 & 0.717 \\
\hline RSV & 5 & 1.7 & 3 & 1.5 & 0.916 \\
\hline Metapneumovirus & 6 & 2.1 & 1 & 0.5 & 0.292 \\
\hline Adenovirus & 4 & 1.4 & 3 & 1.5 & 0.954 \\
\hline $\begin{array}{l}\text { Coronavirus } \\
\text { 229E/ NL63 }\end{array}$ & 4 & 1.4 & 3 & 1.5 & 0.954 \\
\hline Parainfluenza virus & 9 & 3.1 & 4 & 2.0 & 0.646 \\
\hline Rhinovirus & 3 & 1.0 & 3 & 1.5 & 0.865 \\
\hline Sum & 25 & 18 & 10 & 4 & 3 \\
\hline
\end{tabular}

Pearson Chi-squared test ( $X^{2}$ test) was used to calculate statistical significance when comparing between the viral etiology of pneumonia and acute bronchitis 
was 68 years, 51 (61.4\%) of them were males, and 32 (38.6\%) were females. The mean CURB65 score for ICU patients was $2.1 \pm 1.0$. The most identified causative agent was influenza A (6 cases), followed by parainfluenza virus identified in 3 cases, then coronavirus 229E/NL63 and adenovirus in two cases. In addition, influenza $B$ and metapneumovirus were identified only in one case of the ICU patients. Most of the patients in the ICU have had previous co-morbidities. Out of the 83 patients, 79 (95.2\%) had co-morbidities.

Clinical complications have developed in 22 $(26.5 \%)$ cases ( $p$-value $<0.001)$ during their admission period, and death has been the outcome of 14 cases out of these 83 cases $(16.9 \%)$, which means that 14 out of the overall 18 death cases $(77.8 \%)$ were ICU patients ( $p$-value <0.001).

\section{Death cases analysis}

The overall number of fatalities was 18 (3.6\%). With 14 cases, the mortality rate in pneumonia cases $(4.8 \%)$ was higher than the mortality of acute bronchitis (4 cases; $2 \%$ ). The patients median age was 70 years, ten of them were males (55.6\%), while eight were females (44.4\%). The mean CURB65 score of death cases was $2.1 \pm 0.8$. The identified causative agents of death cases have shown that the two cases identified to have viral infection were cases of poly-microbial infection, since both cases were infected with adenovirus, coronavirus, and parainfluenza virus.

Of the 18 patients who died, 17 had co-morbidities, and10 (55.6\%) cases ( $p$-value $<0.001)$ developed medical complications during their admission period.

\section{Discussion}

To the best of our knowledge, this is the first study to investigate causative agents of viral LRTI among Jordanian adults after the outbreak of H1N1pdm009 virus. In the course of the initial pha- se of H1N1pdm009, there was an abrupt upsurge in the rate of severe pneumonia and a change in the age distribution of patients with such illness [25], for which it was essential to investigate the changes in the pattern and severity of viral LRTI among Jordanians, and the changes in the etiology of viral respiratory infections.

In our study, the incidence of LRTI was higher in male patients, where 55\% were males, and $45 \%$ were females. This may be related to the higher smoking percentage among males (35\%) compared with female patients $(8 \%)$ ( $p$-value $<0.001)$. It has been confirmed in many studies that smoking is an independent risk factor for CAP, and this risk increased with the number of pack-years [26-29]. In addition, Individuals aged $>65$ years who had never smoked but were exposed to passive smoking were also at significantly increased risk of CAP, while this effect disappeared in younger individuals $[26,29]$. In the light of the aforementioned results, additional studies should be conducted to investigate the causative agents of LRTI in smokers, non-smokers, ex-smokers, and passive smokers.

Currently, the use of diagnostic methods based on PCR have resulted in an increase the sensitivity of detecting viral and bacterial pathogens associated with LRTI [30]. This indicates that PCR is more rapid and more sensitive than other viral detection techniques [31, 32]. In this study, we attained positive results in $31.7 \%$ of the analyzed patients, with $13.9 \%$ of our patients being positive for viral etiology and $21.2 \%$ for bacterial etiology. We used rapid test-PCR to detect pandemic H1N1pdm009 virus, which is the method of choice for the clinical diagnosis of swine flu H1N virus in respiratory specimens and for differentiating it from seasonal influenza viruses [24], and it showed positive results in $4.2 \%$ of LRTI cases.

Seasonal influenza A virus accounted for approximately $7.1 \%$ of admitted patients with LRTI on whom FTD real-time PCR was done. These numbers are consistent with incidence of influenza $A$ 
infection in Thailand, where $7.4 \%$ of hospitalized CAP patients and $7 \%$ in severe CAP patients were positive for influenza A [33]. Influenza A was also the most common viral pathogen detected in Egyptian patients (8.4\%) [34]. Moreover, parainfluenza viruses was detected in $7.6 \%$ of patients in Jordan, which is nearly as Indonesia, where parainfluenza virus was detected in (7\%) patients [35], and higher than the incidence among Egyptian patients (4.2\%) [34].

RSV is the most common cause of LRTIs in infants and young children worldwide [36]. However, RSV was identified among $4.7 \%$ of our adult patients (4.7\%). This incidence is higher than those in Indonesia and USA $[9,35]$, but lower than that of RSV in Jordanian children detected by direct immunofluorescence technique (12.5\%) [37]. The lower number obtained in this study may be attributed to the lower frequency of RSV in Amman, which was lower than the prevalence reported in Zarqa and in Irbid [38, 39]. This may be due to the difference between these cities in geographical location, crowding and climatic condition [37]. Furthermore, RSV-associated hospitalization rate was found to be the highest in children $<6$ months, for which Middle Eastern children with RSV would benefit from future RSV vaccines and antiviral therapy [40].

Each of influenza B, metapneumovirus, adenovirus, and coronavirus 229E/NL63 was identified in $4.1 \%$ of patients in our study, while only $3.5 \%$ of tested patients were positive for rhinovirus. Although rhinovirus is more often detected as the causative agents of viral pneumonia, its etiological role continues to be questioned [41]. Rhinovirus is more commonly detected in asymptomatic patients [41], which can explain the low yield in this study performed on patients who required hospital admission.

The association between climate factors and respiratory virus infection incidence has been reported in many previous studies, which mainly focused on the low temperature/humidity correlations with influenza virus [2, 42]. Additionally, the absolute humidity and temperature are also associated with hospitalizations due to influenza LRTI $[2,43]$. After observing the seasonal variation in our study, we found that the admission rate for viral LRTI peaked in January.

The proportion of hospitalized patients with pneumonia who are admitted to the ICU ranges between 5 to $20 \%$, depending on hospital and health-system characteristics. The CURB-65 score, which we used to assess the severity of LRTI among our patients, has limited ability in identifying patients who are at increased risk to deteriorate if they were admitted to regular hospital units instead of the ICU [44-46]. Furthermore, the guidelines from the IDSA-ATS suggests that three or more of nine minor criteria should warrant consideration of ICU admission (confusion, elevated blood urea nitrogen, tachypnea, multilobar infiltrates observed on radiograph, hypoxemia, thrombocytopenia, hypotension, hypothermia and leukopenia) [46]. In the light of the previously mentioned suggestion, we should consider the combination of CURB65 score, the IDSAATS guideline and the clinical status of patients in order to ultimately take the final decision of the site of patient's admission.

The average adult in-hospital mortality rate of CAP cases worldwide is approximately $10 \%$ [47]. In the United Kingdom (UK), adult inpatient mortality rate of pneumonia is $5-15 \%$. Although patients with severe pneumonia requiring intensive care unit (ICU) admission, mortality can be as high as 30\% [48-51]. The mortality rate of LRTI in our study was 3.64\%, which is very similar to the mortality rate found in japan in a study published in 2013, which was $3.1 \%$ [52], while it reached approximately $10 \%$ in a study done in Germany published in 2006 [53]. The low mortality rate in Jordan may be as a result of the death of critical patients prior to presentation to hospitals, or death soon after presentation of symptoms, before specimens can be collected [54]. DM was the most common co-morbidity in those 
patients who died, since it was present in 10 out of the 18 patients (55\%) who died, and their median age was 70 years, which raises the concerns regarding the severity of pneumonia among elderly patients with multiple co-morbidities.

There were several limitations to our study. Firstly, FTD was done on 170 (34.34\%) patients only, which might have focused on patients with more severe symptoms. Secondly, only patients who met the criteria of inclusion and who were admitted to the hospital under the care of the pulmonary medicine and critical care primary team were enrolled in the study. These two limitations might have restricted our study's sample size and our ability to find further correlation of viral causes of respiratory tract infection with other medical illnesses. Therefore, we suggest performing a multi-center national study to involve all admitted patients who meet the inclusion criteria from different age groups. In addition, we recommend the performance of an international study that compares between different geographical and environmental settings with standardized methods of virus isolation and patients' inclusion criteria, in order to have a better understanding of the viral etiology of LRTI worldwide.

\section{Conclusion}

Lower respiratory tract infection's causative agents vary throughout the year. It is more common in winter season, especially in January. Influenza $A$ and parainfluenza viruses were the main causative viral agents for LRTI in our study, which highlights the importance of focusing on the administration of seasonal influenza vaccines, especially in elderly patients, as well as patients with comorbidities. We suggest that early laboratory detection of viral agents in patients diagnosed with LRTI would help in decreasing the usage of antibiotics. This will also help in the prevention of antibiotics misuse, which is considered the major cause of antimicrobial resistance.

\section{Authors Contributions}

NO, AM: planned, conceptualized, and supervised the study. They participated in manuscript writing, and approved the final manuscript.

IB, ZO: planned and conceptualized the study, collected the data, conducted literature review, participated in manuscript writing and approved the final manuscript.

NA: performed statistical analysis. He participated in manuscript writing, and approved the final manuscript.

MA, MO, MA, MF, HK: Collected the data, conducted literature review, and participated in manuscript writing, and approved the final manuscript.

MM, RF: Participated in manuscript writing, revised the manuscript, and approved the final manuscript.

\section{Ethical Approval}

The University of Jordan Institutional Review Board approved the study. All procedures performed in studies involving human participants were in accordance with the ethical standards of the institutional and/or national research committee.

\section{Informed Consent}

Informed consent was obtained from all individual before filling the questionnaire.

\section{Data Availability}

The data used for this study is available upon request to corresponding author.

\section{Acknowledgement}

We would like to thank the staff at the Microbiology Laboratory of JUH for their technical help. In addition, we are grateful to all our medical and nursing colleagues for their assistance and cooperation in this study.

\section{Conflict of interest}

The authors declare that they have no conflict of interest. 


\section{References}

1. Little P, Rumsby K, Kelly J, Watson L, Moore M, Warner G, et al. Information leaflet and antibiotic prescribing strategies for acute lower respiratory tract infection: a randomized controlled trial. Jama 2005; 293(24):3029-35.

2. Wiemken $T L$, Mattingly WA, Furmanek SP, Guinn BE, English $\mathrm{CL}$, Carrico R, et al. Impact of Temperature Relative Humidity and Absolute Humidity on the Incidence of Hospitalizations for Lower Respiratory Tract Infections Due to Influenza, Rhinovirus, and Respiratory Syncytial Virus: Results from CommunityAcquired Pneumonia Organization (CAPO) International Cohort Study. Univ Louisville J Respir Infect 2017; 1(3):7.

3. Lozano R, Naghavi M, Foreman K, Lim S, Shibuya K, Aboyans V, et al. Global and regional mortality from 235 causes of death for 20 age groups in 1990 and 2010: a systematic analysis for the Global Burden of Disease Study 2010. Lancet 2012; 380(9859):2095-128.

4. Lim WS, Baudouin SV, George RC, Hill AT, Jamieson C, Le Jeune I, et al. BTS guidelines for the management of community acquired pneumonia in adults: update 2009. Thorax 2009; 64 Suppl 3:iii1-55.

5. Simmerman JM, Chittaganpitch M, Levy J, Chantra S, Maloney $\mathrm{S}$, Uyeki T, et al. Incidence, seasonality and mortality associated with influenza pneumonia in Thailand: 2005-2008. PloS one 2009; 4(11):e7776.

6. Welte T, Torres A, Nathwani D. Clinical and economic burden of community-acquired pneumonia among adults in Europe. Thorax 2012; 67(1):71-9.

7. Marrie TJ, File TM, Jr. Bacterial Pneumonia in Older Adults. Clin Geriatr Med. 2016; 32(3):459-77.

8. Anevlavis S, Petroglou N, Tzavaras A, Maltezos E, Pneumatikos I, Froudarakis $\mathrm{M}$, et al. A prospective study of the diagnostic utility of sputum Gram stain in pneumonia. J Infect 2009; 59(2):83-9.

9. Jain S, Self WH, Wunderink RG, Fakhran S, Balk R, Bramley AM, et al. Community-acquired pneumonia requiring hospitalization among US adults. N Engl J Med 2015; 373(5):415-27.

10. Herrera-Lara S, Fernandez-Fabrellas E, Cervera-Juan A, BlanquerOlivas R. Do seasonal changes and climate influence the etiology of community acquired pneumonia? Arch Bronconeumol 2013; 49(4):140-5.

11. Woodhead MA, Macfarlane JT, McCracken JS, Rose DH, Finch RG. Prospective study of the aetiology and outcome of pneumonia in the community. Lancet 1987; 1(8534):671-4.

12. Ruuskanen O, Lahti E, Jennings LC, Murdoch DR. Viral pneumonia. Lancet 2011; 377(9773):1264-75.

13. Fouchier RA, Rimmelzwaan GF, Kuiken T, Osterhaus AD. Newer respiratory virus infections: human metapneumovirus, avian influenza virus, and human coronaviruses. Curr Opin Infect Dis 2005; 18(2):141-6.

14. Larcher C, Jeller V, Fischer $H$, Huemer HP. Prevalence of respiratory viruses, including newly identified viruses, in hospitalised children in Austria. Eur J Clin Microbiol Infect Dis 2006; 25(11):681-6.

15. Marcos MA, Esperatti $M$, Torres A. Viral pneumonia. Curr Opin Infect Dis 2009; 22(2):143-7.
16. Arens MQ, Buller RS, Rankin A, Mason S, Whetsell A, Agapov E, et al. Comparison of the Eragen Multi-Code Respiratory Virus Panel with Conventional Viral Testing and Real-Time Multiplex PCR Assays for Detection of Respiratory Viruses. J Clin Microbiol 2010; 48(7):2387-95.

17. Do $A H$, van Doorn HR, Nghiem MN, Bryant JE, Hoang TH, Do $\mathrm{QH}$, et al. Viral etiologies of acute respiratory infections among hospitalized Vietnamese children in Ho Chi Minh City, 20042008. Plos one 2011; 6(3):e18176.

18. Tiveljung-Lindell A, Rotzen-Ostlund $M$, Gupta $S$, Ullstrand R, Grillner L, Zweygberg-Wirgart B, et al. Development and implementation of a molecular diagnostic platform for daily rapid detection of 15 respiratory viruses. J Med Virol 2009; 81(1):167-75.

19. Garner JS, Jarvis WR, Emori TG, Horan TC, Hughes JM. CDC definitions for nosocomial infections, 1988. Am J Infect Control 1988; 16(3):128-40.

20. Society AT, America IDSo. Guidelines for the management of adults with hospital-acquired, ventilator-associated, and healthcare-associated pneumonia. Am J Respir Crit Care Med 2005; 171(4):388.

21. Singer M, Deutschman CS, Seymour CW, Shankar-Hari M, Annane $D$, Bauer $M$, et al. The third international consensus definitions for sepsis and septic shock (Sepsis-3). Jama 2016; 315(8):801-10

22. Mandell LA, Wunderink RG, Anzueto A, Bartlett JG, Campbell GD, Dean NC, et al. Infectious Diseases Society of America/ American Thoracic Society consensus guidelines on the management of community-acquired pneumonia in adults. Clin infect dis 2007; 44(Supplement_2):S27-S72.

23. Malhotra B, Swamy MA, Reddy PJ, Kumar N, Tiwari JK. Evaluation of custom multiplex real-time RT-PCR in comparison to fasttrack diagnostics respiratory 21 pathogens kit for detection of multiple respiratory viruses. Virol J 2016; 13(1):91.

24. Chan K, Lai S, Poon L, Guan Y, Yuen K, Peiris J. Analytical sensitivity of rapid influenza antigen detection tests for swineorigin influenza virus (H1N1). J Clin Virol 2009; 45(3):205-7.

25. Chowell G, Bertozzi SM, Colchero MA, Lopez-Gatell H, AlpucheAranda C, Hernandez M, et al. Severe respiratory disease concurrent with the circulation of H1N1 influenza. N Engl J Med 2009; 361(7):674-9

26. Almirall J, Bolibar I, Serra-Prat M, Roig J, Carandell E, Agustí $M$, et al. New evidence of risk factors for community-acquired pneumonia: a population-based study. Europ respir J 2008; 31(6):1274-84.

27. Almirall J, Serra-Prat M, Bolíbar I, Palomera E, Roig J, Carandell $\mathrm{E}$, et al. Passive smoking at home is a risk factor for communityacquired pneumonia in older adults: a population-based casecontrol study. BMJ open 2014; 4(6):e005133.

28. Jackson ML, Nelson JC, Jackson LA. Risk Factors for CommunityAcquired Pneumonia in Immunocompetent Seniors. J Am Geriatr Soc 2009; 57(5):882-8.

29. Torres A, Blasi F, Dartois N, Akova M. Which individuals are at increased risk of pneumococcal disease and why? Impact of COPD, asthma, smoking, diabetes, and/or chronic heart disease on community-acquired pneumonia and invasive pneumococcal disease. Thorax 2015:thoraxjnl-2015-206780. 
30. Bartlett JG. Diagnostic tests for agents of community-acquired pneumonia. Clin Infect Dis 2011; 52(suppl_4):S296-S304.

31. Johansson N, Kalin M, Tiveljung-Lindell A, Giske CG, Hedlund J. Etiology of community-acquired pneumonia: increased microbiological yield with new diagnostic methods. Clin Infect Dis 2010; 50(2):202-9.

32. Oosterheert JJ, Van Loon AM, Schuurman R, Hoepelman Al, Hak E, Thijsen S, et al. Impact of rapid detection of viral and atypical bacterial pathogens by real-time polymerase chain reaction for patients with lower respiratory tract infection. Clin Infect Dis 2005; 41(10):1438-44.

33. Olsen S, Thamthitiwat S, Chantra S, Chittaganpitch M, Fry A, Simmerman J, et al. Incidence of respiratory pathogens in persons hospitalized with pneumonia in two provinces in Thailand. Epidemiol Infect 2010; 138(12):1811-22.

34. Rowlinson E, Dueger E, Mansour A, Azzazy N, Mansour H, Peters $L$, et al. Incidence and etiology of hospitalized acute respiratory infections in the Egyptian Delta. Influenza Other Respir Viruses 2017; 11(1):23-32.

35. Farida H, Gasem MH, Suryanto A, Keuter M, Zulkarnain $N$, Satoto $B$, et al. Viruses and Gram-negative bacilli dominate the etiology of community-acquired pneumonia in Indonesia, a cohort study. Int J Infect Dis 2015; 38:101-7.

36. Bont L, Checchia PA, Fauroux B, Figueras-Aloy J, Manzoni P, Paes $B$, et al. Defining the epidemiology and burden of severe respiratory syncytial virus infection among infants and children in western countries. Infect Dis Ther 2016; 5(3):271-98.

37. Al-Toum R, Bdour S, Ayyash H. Epidemiology and clinical characteristics of respiratory syncytial virus infections in Jordan. J Trop Pediatr 2006; 52(4):282-7.

38. Bdour S. Respiratory syncytial virus subgroup $A$ in hospitalized children in Zarqa, Jordan. Ann Trop Paediatr 2001; 21(3):253-61.

39. Meqdam MM, Nasrallah GK. Enhanced detection of respiratory syncytial virus by shell vial in children hospitalised with respiratory illnesses in northern Jordan. J Med Virol 2000; 62(4):518-23.

40. Halasa N, Williams J, Faouri S, Shehabi A, Vermund SH, Wang L, et al. Natural history and epidemiology of respiratory syncytial virus infection in the Middle East: Hospital surveillance for children under age two in Jordan. Vaccine 2015; 33(47):647987.

41. Galván JM, Rajas O, Aspa J. Review of non-bacterial infections in respiratory medicine: viral pneumonia. Arch Bronconeumol (English Edition) 2015; 51(11):590-7.

42. Shaman J, Kohn M. Absolute humidity modulates influenza survival, transmission, and seasonality. Proc Natl Acad Sci USA 2009; 106(9):3243-8.

43. Lowen AC, Steel J. Roles of humidity and temperature in shaping influenza seasonality. J Virol 2014; 88(14):7692-5.

44. Fine MJ, Auble TE, Yealy DM, Hanusa BH, Weissfeld LA, Singer $\mathrm{DE}$, et al. A prediction rule to identify low-risk patients with community-acquired pneumonia. N Engl J Med 1997; 336(4):243-50.

45. Lim W, Van der Eerden M, Laing R, Boersma W, Karalus N, Town $G$, et al. Defining community acquired pneumonia severity on presentation to hospital: an international derivation and validation study. Thorax 2003; 58(5):377-82.
46. Wunderink RG, Waterer GW. Community-acquired pneumonia. N Engl J Med 2014; 370(6):543-51.

47. Yende S, Angus DC, Ali IS, Somes G, Newman AB, Bauer D, et al. Influence of comorbid conditions on long-term mortality after pneumonia in older people. J Am Geriatr Soc 2007; 55(4):51825.

48. Community-acquired pneumonia in adults in British hospitals in 1982-1983: a survey of aetiology, mortality, prognostic factors and outcome. The British Thoracic Society and the Public Health Laboratory Service. Q J Med 1987; 62(239):195-220.

49. Macfarlane JT, Finch RG, Ward MJ, Macrae AD. Hospital study of adult community-acquired pneumonia. Lancet 1982; 2(8292):255-8.

50. Mongardon N, Max A, Bougle A, Pene F, Lemiale V, Charpentier $J$, et al. Epidemiology and outcome of severe pneumococcal pneumonia admitted to intensive care unit: a multicenter study. Crit Care 2012; 16(4):R155.

51. White RJ, Blainey AD, Harrison KJ, Clarke SK. Causes of pneumonia presenting to a district general hospital. Thorax 1981; 36(8):566-70.

52. Ishiguro T, Takayanagi N, Yamaguchi S, Yamakawa $H$, Nakamoto K, Takaku Y, et al. Etiology and factors contributing to the severity and mortality of community-acquired pneumonia. Intern Med 2013; 52(3):317-24.

53. Welte T, Marre R, Suttorp N. What is new in the treatment of community-acquired pneumonia? Med Klin (Munich) 2006; 101(4):313-20.

54. Feikin DR, Hammitt LL, Murdoch DR, O'brien KL, Scott JAG. The enduring challenge of determining pneumonia etiology in children: considerations for future research priorities. Clin infect dis 2017; 64(suppl_3):S188-S96.

\section{Publish in The International}

\section{Arabic Journal of Antimicrobial Agents}

The Journal is an open access peer-reviewed journal that publishes scientific papers about all aspects of antimicrobials. The journal will publish original research articles, reviews, brief reports and case reports dealing with basic and clinical antibacterial agents, antiviral, antiprotozoals, antituberculuous, antifungal and antihelminthes agents. All manuscripts must be prepared in English, and are subject to a rigorous and fair peer-review process. Accepted papers will immediately appear online. The journal aims to advance the knowledge, attitude and the research of chemotherapy in the Arabic world in cooperation with international, national scientific and public societies as well as research centers with similar aims and objectives. 